\title{
First results from the CAWSES-India Tidal Campaign
}

\author{
S. Gurubaran ${ }^{1}$, D. Narayana Rao ${ }^{2}$, G. Ramkumar ${ }^{3}$, T. K. Ramkumar ${ }^{2}$, G. Dutta ${ }^{4}$, and B. V. Krishna Murthy \\ ${ }^{1}$ Equatorial Geophysical Research Laboratory, Indian Institute of Geomagnetism, Tirunelveli, India \\ ${ }^{2}$ National Atmospheric Research Laboratory, Gadanki, India \\ ${ }^{3}$ Space Physics Laboratory, Vikram Sarabhai Space Centre, Thiruvananthapuram, India \\ ${ }^{4}$ Anwarul-uloom College, Hyderabad, India \\ 547/20, 3rd Main Road, Gandhi Nagar, Adayar, Chennai, India
}

Received: 7 November 2007 - Revised: 15 April 2008 - Accepted: 29 April 2008 - Published: 5 August 2008

\begin{abstract}
The first CAWSES-India Tidal Campaign was conducted by the Indian scientific community during MarchApril 2006. The objectives of this campaign were: (1) To determine the characteristics of tides in the troposphere and lower stratosphere $(0-20 \mathrm{~km})$ and mesosphere and lower thermosphere (MLT) region $(80-100 \mathrm{~km})$, (2) to explore and identify what lower atmospheric processes drive middle atmospheric tides in the Indian continental region and (3) to provide information on those short-term variabilities of MLT tides that are likely to have an impact on the ionospheric variabilities and contribute to the upper atmospheric weather. Data sets from experiments conducted at the three low latitude radar sites, namely, Trivandrum $\left(8.5^{\circ} \mathrm{N}\right.$, $\left.76.9^{\circ} \mathrm{E}\right)$, Tirunelveli $\left(8.7^{\circ} \mathrm{N}, 77.8^{\circ} \mathrm{E}\right)$ and Gadanki $\left(13.5^{\circ} \mathrm{N}\right.$, $79.2^{\circ} \mathrm{E}$ ) and fortnightly rocket launches from Thumba were made use of in this study. An important observational finding reported in this work is that the radar observations at Tirunelveli/Trivandrum indicate the presence of 15-20 day modulation of diurnal tide activity at MLT heights during the February-March period. A similar variation in the OLR fields in the western Pacific (120-160 longitude region) suggests a possible link between the observed tidal variabilities and the variations in the deep tropical convection through the nonmigrating tides it generates.
\end{abstract}

Keywords. Meteorology and atmospheric dynamics (Middle atmosphere dynamics; Thermospheric dynamics; Waves and tides)

\section{Introduction}

Atmospheric tides are global-scale perturbations in temperatures, winds and species densities that have origin in many sources: solar UV and IR absorption by ozone and water vapour and molecular and atomic oxygen at stratospheric and

Correspondence to: S. Gurubaran

(gurubara@iigs.iigm.res.in) ionospheric heights (e.g. Hagan, 1996), respectively, longitudinal inhomogeneities in the absorbing gases (e.g. Lieberman et al., 2003), release of latent heat in deep convective clouds (e.g. Hamilton, 1981; Hagan and Forbes, 2002), landsea distribution (e.g. Tsuda and Kato, 1989) and non-linear interaction of planetary waves and tides leading to generation of tides of higher zonal wavenumbers (e.g. Hagan and Roble, 2001). They are the dominant dynamical features of the mesosphere-lower thermosphere (MLT) region (80$100 \mathrm{~km}$ ), especially in the tropical region. At these heights, the tides may be transient, or dissipate energy and momentum, as damping processes like viscosity, thermal conduction or ion drag become important (e.g. Lindzen and Blake, 1971). All these effects have profound influences on the energy and momentum budgets of this important transition region (e.g. Lindzen, 1981).

In recent years significant attention is being paid to understanding the spatial and temporal variabilities of the diurnal tide in the MLT region revealed by ground-based and satellite-borne investigations pursued over the tropical region (Burrage et al., 1995; Chang and Avery, 1997; Khattatov et al., 1997; Vincent et al., 1998; Tsuda et al., 1999; Gurubaran and Rajaram, 1999; Talaat and Lieberman, 1999; Oberheide and Gusev, 2002; Forbes et al., 2003; Lieberman et al., 2004; Gurubaran et al., 2005; Oberheide et al., 2006). The modelling efforts in the past varied from linear mechanistic tidal models (Forbes, 1982; Hagan et al., 1995) to complex middle atmospheric general circulation models (e.g. McLandress et al., 1997; Miyahara et al., 1999; Hagan and Roble, 2001) and have contributed to our understanding of the processes that participate in the generation of tides and those that influence their propagation. However, direct observation of tides in the MLT region and those carried out in the troposphere and lower stratosphere are yet to provide any evidence for their association with the generating mechanisms in the lower atmosphere or propagation conditions existing in the middle atmosphere.

Published by Copernicus Publications on behalf of the European Geosciences Union. 

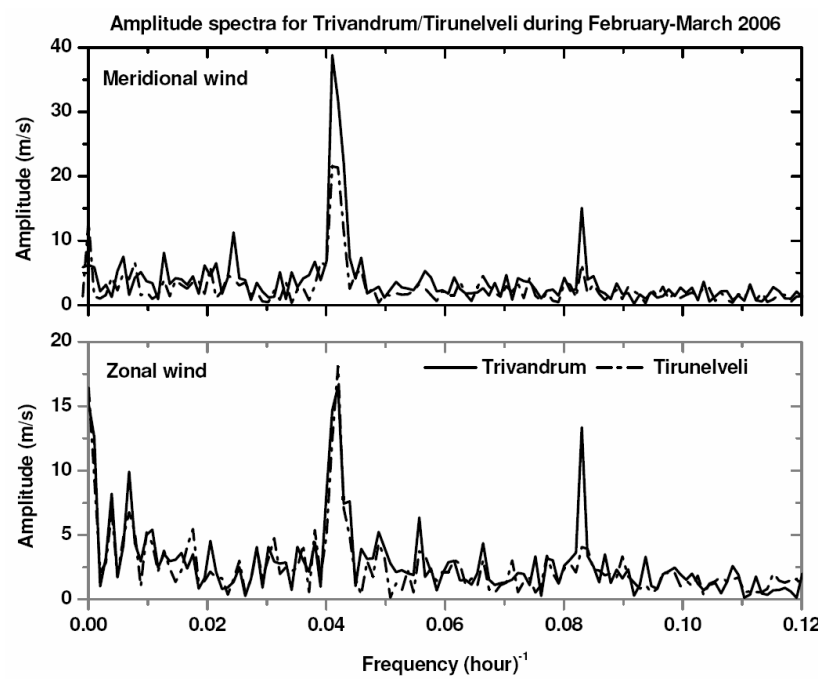

Fig. 1. Comparison of the amplitude spectra for the zonal (bottom panel) and meridional (top panel) winds at $88 \mathrm{~km}$ during FebruaryMarch 2006 between the MW radar (continuous curves) and MF radar (dashed curves) observations at Trivandrum and Tirunelveli, respectively.

An Indian Climate and Weather of Sun-Earth System (CAWSES) programme is being pursued in India with a number of research institutions hosting a variety of groundbased instruments at several sites. The first CAWSES-India Tidal Campaign was held during February-April 2006 by the members of the Working Group 3 (Atmospheric Coupling Processes) of CAWSES-India programme with the principal objective of determining the characteristics of tides in the troposphere and lower stratosphere $(0-20 \mathrm{~km})$ and mesospherelower thermosphere $(80-100 \mathrm{~km})$ regions. Holding a campaign of this kind during a specific period would lead to an assessment of atmospheric conditions which favour propagation of certain tidal modes that make significant impacts on the middle atmospheric momentum and energy budgets. It was envisaged that this campaign would have relevance to the activities of Working Group 2 (Space Weather: Science and Applications) of CAWSES-India because the quiettime upper atmospheric weather has an important source of variability in atmospheric perturbations or waves propagating upwards from the lower and middle atmosphere.

As part of this tidal campaign, experiments were conducted at the low latitude radar sites, namely, Trivandrum $\left(8.5^{\circ} \mathrm{N}, 76.9^{\circ} \mathrm{E}\right)$, Tirunelveli $\left(8.7^{\circ} \mathrm{N}, 77.8^{\circ} \mathrm{E}\right)$ and Gadanki $\left(13.5^{\circ} \mathrm{N}, 79.2^{\circ} \mathrm{E}\right)$ during March-April 2006. Though the MF radar at Tirunelveli and the SKiYMET meteor wind (MW) radar at Trivandrum were on routine operation yielding useful data on tidal winds in the MLT region, the MST radar at Gadanki was operated in the diurnal cycle mode yielding information on tidal parameters in the troposphere and lower stratosphere $(3-25 \mathrm{~km})$. Fortnightly rocket launches from Thumba carried out as part of the Middle
Atmospheric Dynamics (MIDAS) programme of the Indian Space Research Organization were scheduled over a period of three months with observations separated by four hours in local time. This schedule was aimed to enable estimates of average diurnal tide characteristics representing the threemonth period, February-April 2006.

The present work, the first of its kind from India, combines data sets from the three radars and the rocket-borne experiment in an attempt to delineate the diurnal tide variabilities during this period and identify the underlying forcing mechanisms. The first results from this campaign being presented in this work examine the differences in the tidal characteristics revealed by the MF and MW radars. It would be shown in Sect. 3.1 that though the tidal phases in both zonal and meridional components and the tidal amplitudes for the zonal component agree quite well between the two sites, the MF radar amplitude estimates for the meridional component are significantly smaller than the MW radar estimates. Section 3.2 examines the average tidal characteristics derived from the rocket observations and the tidal amplitudes and phases in the troposphere-lower stratosphere region. Similar to a study pursued earlier (Gurubaran et al., 2005), a correlative analysis was performed with the radar observations and the satellite-derived daily Outgoing Longwave Radiance (OLR) fields and 3-hourly rainfall data from TRMM in order to explain the presence of 15-20 day variations in the observed tidal parameters over Tirunelveli/Trivandrum. Results from this analysis are presented in Sect. 3.3.

\section{Observations and data analysis}

The MF radar at Tirunelveli uses the spaced antenna technique to determine winds in the MLT region (Vincent, 1984; Vincent and Lesicar, 1991; Rajaram and Gurubaran, 1998) and has been operating at Tirunelveli since 1992. Utilizing a broad beam and adopting the full correlation analysis developed by Briggs (1984), the MF radar measures the horizontal velocities of the irregularities that are presumed to move with the background neutral wind. The meteor wind radar operating at Trivandrum is the commercially available SKiYMET system and utilizes echoes arising from meteor trails for wind detection. The data analysis and the method of wind retrieval for the SKiYMET system are described in Hocking (2001).

Both MF and MW radar observations grouped into 5-day segments were subjected to harmonic analysis and the amplitudes and phases of the diurnal components of the zonal and meridional winds were retrieved in a least squares sense. Though both the instruments were being routinely operated, a one-month data gap was present at Tirunelveli between 22 March and 23 April 2006 and therefore the tidal analysis was performed for the period 1 February-22 March 2006.

The Indian MST radar located at Gadanki is a highpower VHF phased array operating at $\sim 53 \mathrm{MHz}$ in coherent backscatter mode. The system details are described in Rao et 

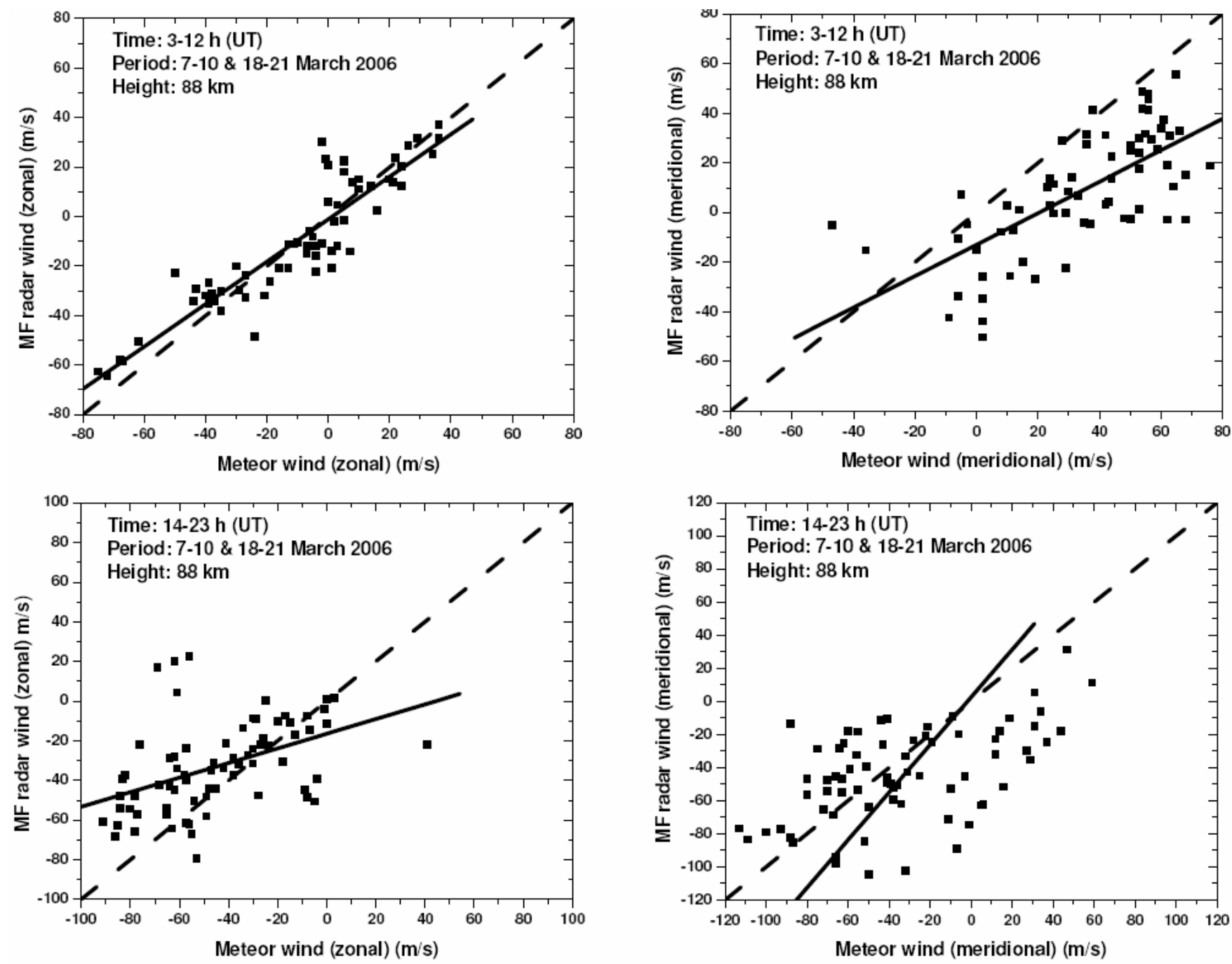

Fig. 2. Comparison of hourly wind estimates made with MW radar at Trivandrum and MF radar at Tirunelveli during the 4-day intervals, 7-10 March 2006 and 18-21 March 2006. The top panels are for the daytime measurements (07:00-10:00 UT) and the bottom panels are for nighttime measurements (14:00-23:00 UT).

al. (1995). During the tidal campaign, the MST radar was operated in the diurnal cycle mode wherein the Doppler spectra were obtained in the height range $3-20 \mathrm{~km}$ at $150-\mathrm{m}$ intervals using successive beams pointed towards vertical and $10^{\circ}$ off zenith in the east, west, north and south directions. Every wind measurement was obtained from a sequence of Doppler spectra accumulated for $10 \mathrm{~min}$ every hour. The time series for the zonal, meridional and vertical winds thus obtained were for the 24-h period with a time resolution of $1 \mathrm{~h}$ and height resolution of $150 \mathrm{~m}$. Further details of such an experiment can be found in Sasi et al. (1998). There were 4-5 diurnal cycles of operation conducted during alternate weeks corresponding to the following windows: 7-11 March, 1822 March, 3-6 April and 17-22 April. Composite hourly values from these 4-5 day segments were used to derive the amplitudes and phases of diurnal tide in the troposphere and lower stratosphere probed by the MST radar.
The fortnightly RH-200 rocket launches at Thumba yielded wind velocity profiles in the height region $20-65 \mathrm{~km}$ using the chaff releases (Ramkumar et al., 2006). The launch schedule during February-April 2006 was designed in order to have composite 24-h local time coverage at a time resolution of four hours. This had enabled the retrieval of amplitudes and phases of the diurnal tide in the middle atmospheric region over Thumba representing the 3-month campaign duration. 

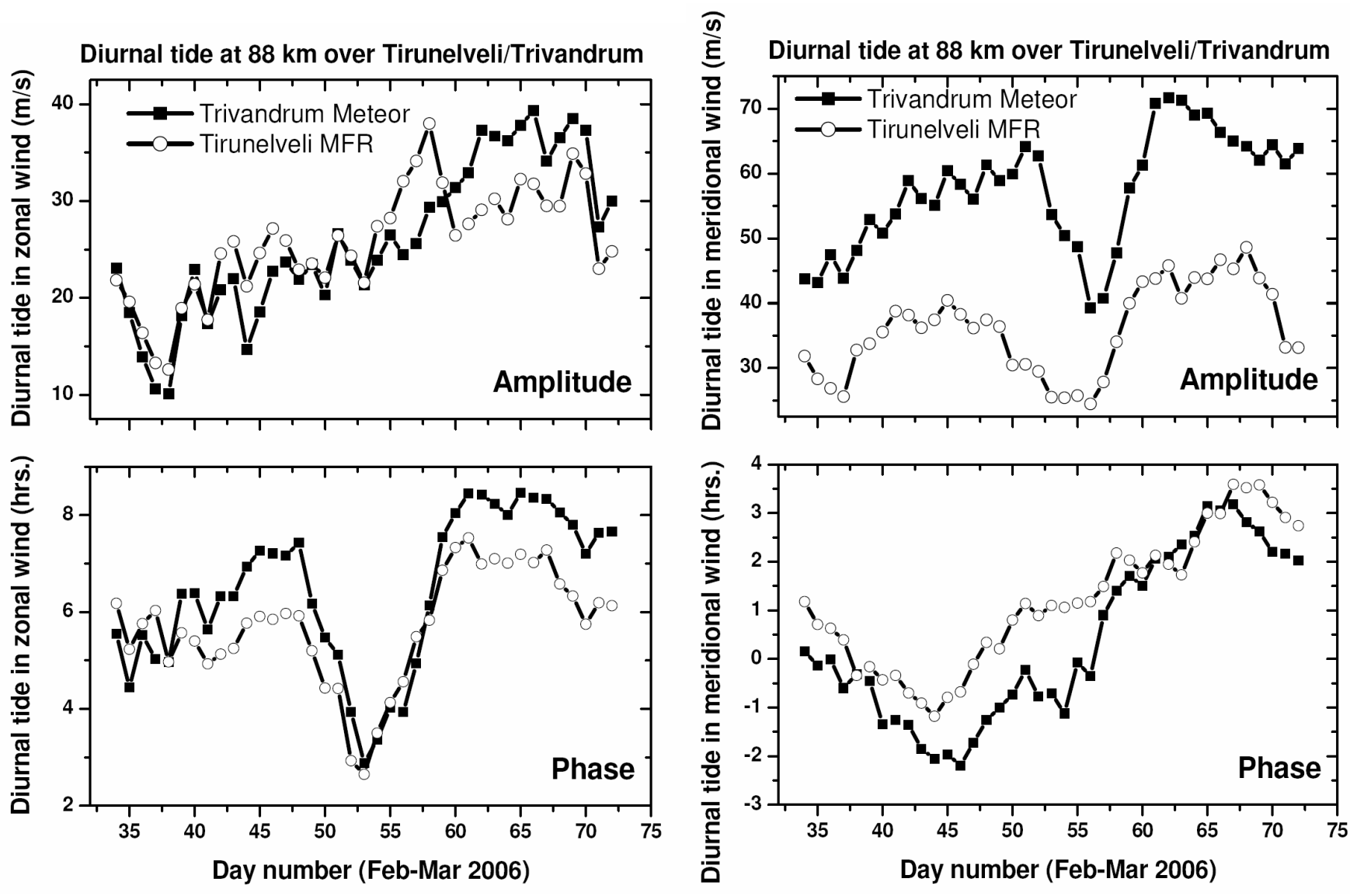

Fig. 3. Comparison for the amplitudes (top panels) and phases (bottom panels) of the diurnal tide at $88 \mathrm{~km}$.

\section{Results}

3.1 Comparison of hourly wind and tidal estimates with MW and MF radar measurements

We begin this section by showing in Fig. 1 the amplitude spectra of the zonal and meridional winds at $88 \mathrm{~km}$ derived from the 1024-point data sets obtained with the MW radar at Trivandrum and MF radar at Tirunelveli during FebruaryMarch 2006. It may be noted that the two MLT radar sites were separated by less than $100 \mathrm{~km}$. Both the radar measurements reveal the large diurnal component that dominates the hourly wind spectra during this period. A significant difference between the two measurement sets is that the meridional component of the diurnal tide estimated with the MF radar data is considerably smaller than that estimated with the MW radar. The amplitudes of the zonal component are nearly the same over the two sites.

In order to examine these differences closely, we plot in Fig. 2 the scatter plots for the individual hourly winds measured at the two radar sites. The top panels depict the comparison for the daytime (03:00-12:00 UT) measurements and the bottom panels are for the nighttime (14:00-23:00 UT) ob- servations. As per the convention adopted by the MLT radar community, eastward (westward) zonal wind is assigned a positive (negative) direction whereas northward (southward) meridional motions are assigned positive (negative) values. As can be seen in Fig. 2, the hourly zonal winds over the two sites during daytime compare quite well in both direction and magnitude. During nighttime, though several points tend to lie along the dashed curve representing good agreement, there are few points that differ considerably. Regarding the comparison for meridional winds, the MW radar tends to detect a larger northward motion during daytime when compared to what the MF radar detects. Significant differences are noticed for the nighttime measurements as well.

We extend the above comparison to the amplitudes and phases of the diurnal tide estimated with the two radar data sets. The results are shown in Fig. 3. Five-day data segments were used to derive the tidal parameters at one-day time invervals. The chosen period was from 1 February to 22 March 2006. Like with the hourly wind comparison, the amplitudes for the zonal component agree quite well during most of this period and the phases differ up to $2 \mathrm{~h}$. On the other hand, the MF radar has yielded smaller amplitude for the meridional component. The phases in the meridional direction agree 

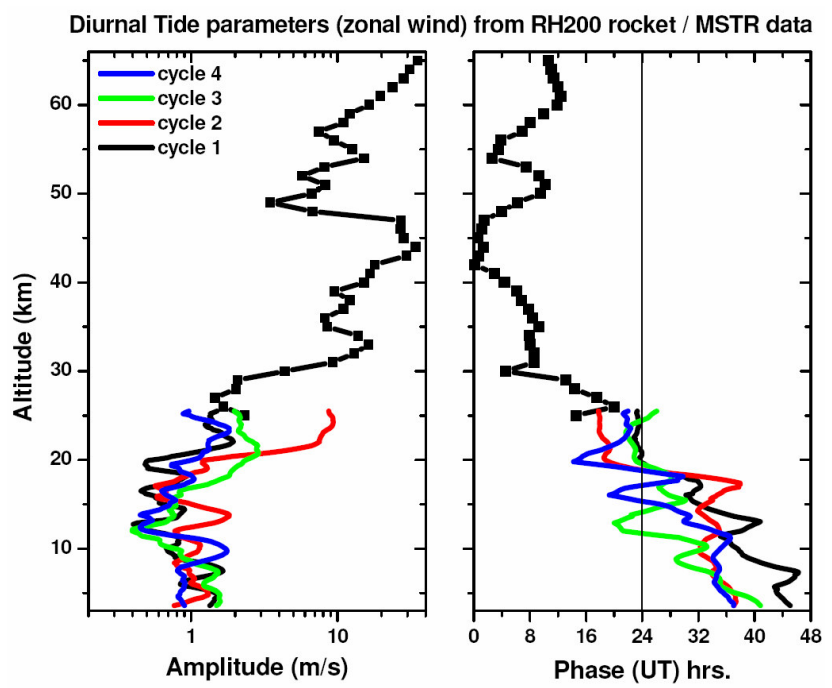

Fig. 4. Altitude profiles of amplitude and phase of the diurnal tide in zonal wind representing the average characteristics derived from the fortnightly rocket launches during February-April 2006 and MST radar derived parameters for the four cycles (refer to text for the dates).

reasonably well. We attribute the differences in the estimated tidal parameters at the two sites to the differences in the measurement techniques.

A noticeable feature in the comparative plots shown in Fig. 3 is that though the absolute magnitudes differ (the largest is for the amplitude in the meridional wind), the variations in the tidal parameters estimated over the two sites are remarkably similar. A gradual increase in the amplitude of the zonal component from $\sim 10 \mathrm{~m} / \mathrm{s}$ around day number 38 to $\sim 40 \mathrm{~m} / \mathrm{s}$ on day 70 could be seen in both the wind measurements. A 4-6h transition in phase in the zonal wind around day number 50 is also noticed in both the data sets. Both radars detected smallest amplitude in the meridional component around day number 55 though the amplitudes differed ( $\sim 25 \mathrm{~m} / \mathrm{s}$ with MFR and $\sim 40 \mathrm{~m} / \mathrm{s}$ with MWR).

3.2 Diurnal tide parameters in the lower and middle atmosphere derived from RH-200 rocket and MST radar data

The amplitudes and phases of the diurnal tide in zonal and meridional winds estimated from the rocket observations for the height region $25-65 \mathrm{~km}$ representing the 3-month duration (February-April) are shown in Figs. 4 and 5. The tidal parameters retrieved from the MST radar data obtained during the four 4-5 day diurnal cycles for the lower altitude region $3-25 \mathrm{~km}$ are also depicted in these figures. Because the MST radar derived amplitudes are an order of magnitude smaller than the rocket derived values, the amplitudes on the left panels are plotted in logarithmic scale. The phases for the lower altitude region are scaled to read values in the range
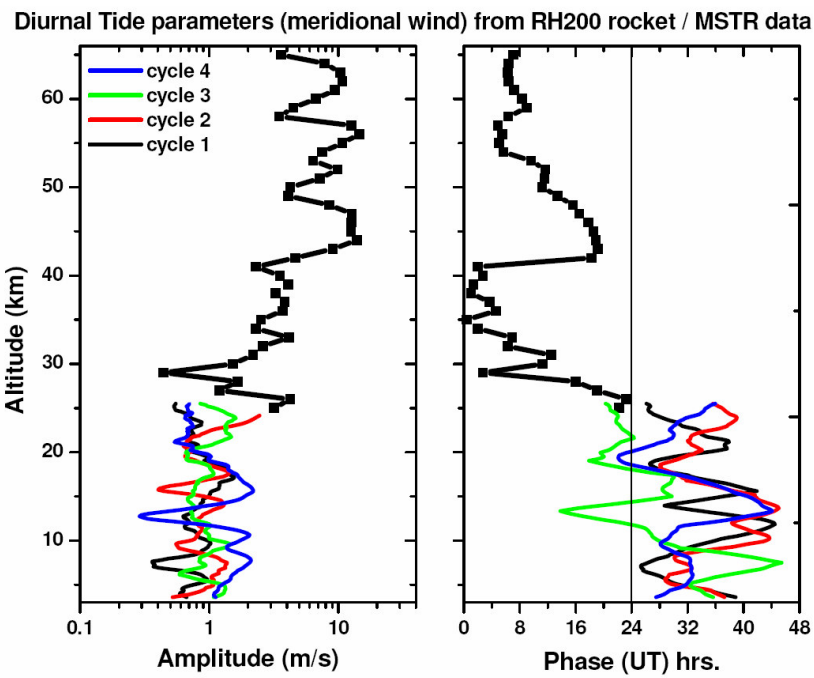

Fig. 5. Same as Fig. 4 but for meridional wind.

24-48 h so that the continuity in phase between the two regions (3-25 km and 25-65 km) can be examined.

The seasonal and long-term (SAO and QBO) wind contributions derived using the long-term observations (20022005) were removed before subjecting the rocket derived data sets to the time series analysis. The profiles shown in Figs. 5 and 6 for the rocket probing region therefore represent the average tidal characteristics over the 3-month duration (February-April 2006).

The diurnal tide in zonal wind has large amplitude ( $\sim 35 \mathrm{~m} / \mathrm{s}$ ) at a height of $45 \mathrm{~km}$. The amplitude of the meridional component at that height is $\sim 15 \mathrm{~m} / \mathrm{s}$. The amplitude in the zonal direction tends to increase above $60 \mathrm{~km}$ where the amplitude of the meridional component is in the range 5$10 \mathrm{~m} / \mathrm{s}$. A remarkable feature noticed in the phase profiles is the clear downward progression in both zonal and meridional components in the lower altitude region $(25-40 \mathrm{~km})$ yielding a vertical wavelength of $\sim 15 \mathrm{~km}$. The phase in the meridional direction continues to advance to earlier hours above $45 \mathrm{~km}$ but with less clarity. The diurnal tide in the zonal wind reveals an oscillating phase behaviour above $40 \mathrm{~km}$. Phases varying in opposite directions between 35 and $50 \mathrm{~km}$ accompanied by an amplitude maximum at $45 \mathrm{~km}$ provides indications for interference effects between two or more modes.

Figures 4 and 5 also show the altitude profiles of the amplitudes and phases of the diurnal tide in zonal and meridional winds in the altitude region $3-25 \mathrm{~km}$ as estimated from the data obtained by the MST radar at Gadanki during the four diurnal cycles of operation. The amplitudes and phases were smoothed in altitude with a running mean. The amplitude profiles of the zonal component revealed in Fig. 4 during cycles 1 and 4 are nearly similar, whereas during cycle 2 a significant enhancement in tidal amplitudes above $20 \mathrm{~km}$ is noticed. The amplitude profiles of the meridional component 


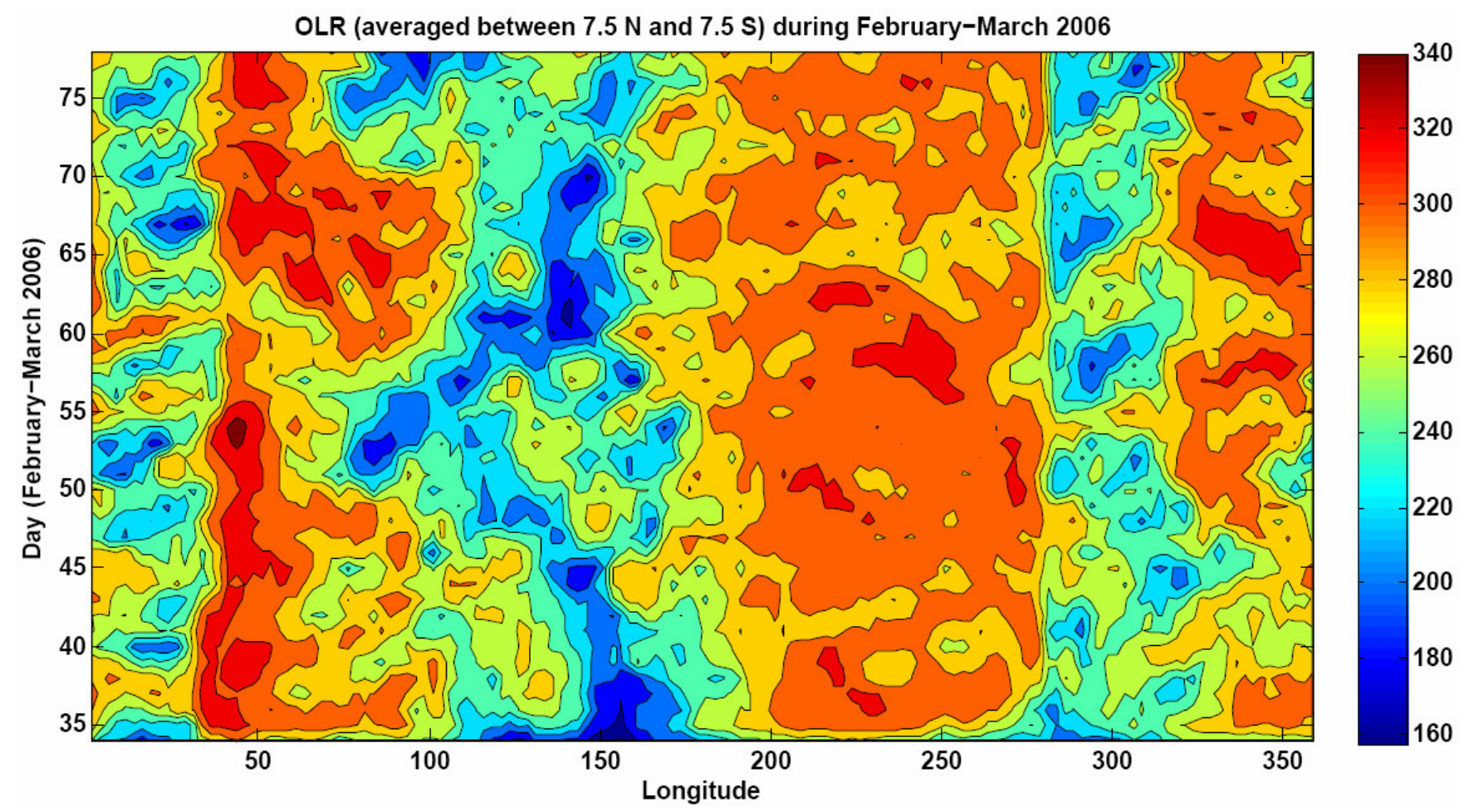

Fig. 6. Daily OLR averaged between $7.5^{\circ} \mathrm{N}$ and $7.5^{\circ} \mathrm{S}$ plotted versus longitude.

shown in Fig. 5 exhibit greater variability between the four cycles. The phases in the zonal direction reveal descending trends on the whole with vertical wavelength estimates $(\sim 15 \mathrm{~km})$ similar to those derived for the rocket probing region $(25-40 \mathrm{~km})$. The phases in the meridional components are very irregular and no consistent trend in altitude could be deciphered in this direction. This irregular behaviour could be due to random variations induced by short-period gravity waves. It may be noted that MST radar measurements used for this analysis were made for only $10 \mathrm{~min}$ during every hour of each of the diurnal cycles from which composite 24-hourly means were derived. The MST radar observations of diurnal tide parameters need to be interpreted with caution with this limitation in mind.

3.3 Relationship between deep tropical convection and tidal variabilities in the MLT region

The emphasis in this section is to explore a possible link between the deep tropical convection and the diurnal tide variabilities observed in the MLT region. Earlier work by Gurubaran et al. (2005) that made use of simultaneous MLT radar observations from Jakarta and Tirunelveli indicated a possible role of the deep tropical convection in causing the diurnal tide variabilities over Jakarta over seasonal time scales. We extend that idea to the present analysis and explore whether the observed tidal variabilities will have any relationship with the short-term variations in convective activity.

For this analysis, we used two types of data sets: (1) the daily OLR provided by the NOAA-NCEP Climate Prediction Center and (2) the 3-hourly rainfall rates available from the Tropical Rainfall Measuring Mission (TRMM) satellite data archives. Both the daily OLR and the 3-hourly rainfall rates were first averaged over the latitude region $7.5^{\circ} \mathrm{N}-7.5^{\circ} \mathrm{S}$ at every longitude yielding a data set that represents variations in longitude (with a resolution of $2.5^{\circ}$ for OLR and $0.25^{\circ}$ for rainfall rate) as well as over time (at a resolution of one day for OLR and $3 \mathrm{~h}$ for rainfall rate). The three-hourly rainfall rates for every longitude bin were further subjected to harmonic analysis to yield diurnal amplitudes. Because the diurnal latent heat release drives the diurnal precipitation, the diurnal amplitudes derived from the TRMM rainfall rates are expected to represent the strength of the nonmigrating tide that could be generated by the deep convective forcing.

We first show the spatial and temporal variabilities of the low latitude daily OLR for the period February-March 2006 in Fig. 6. Regions with low OLR are anticipated to be convectively active. During this period of the tidal campaign, the longitude region between 120 and $160^{\circ} \mathrm{E}$ is seen to be characterized by deep convective activity. The convection appears first in the longitude region around $150^{\circ} \mathrm{E}$ during the first week of February and migrates gradually towards the west. Between day numbers 50 and 60 , an eastward 
OLR $\left( \pm 7.5^{\circ}\right)$ and diurnal tide in meridional wind at MLT heights
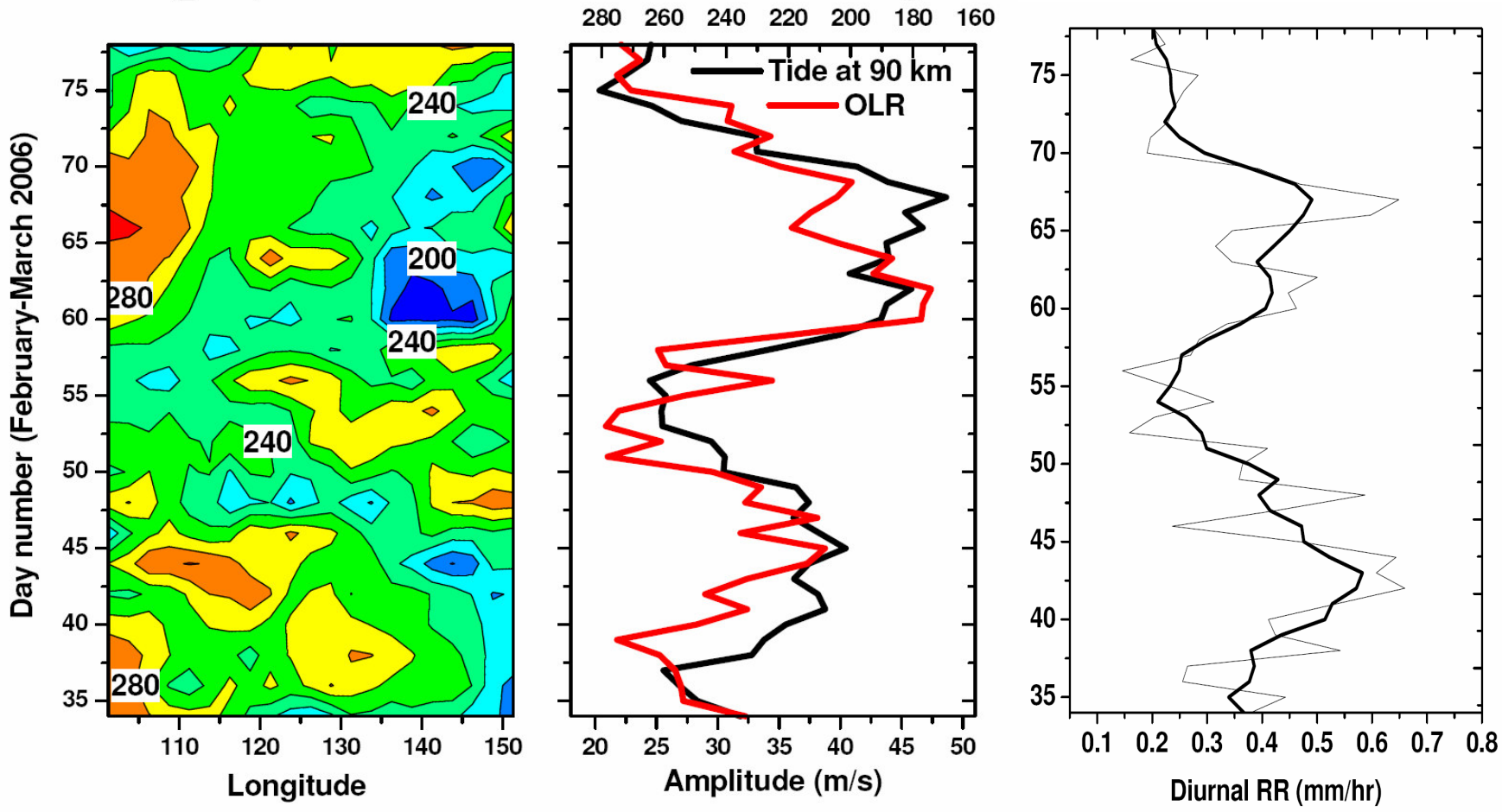

Fig. 7. Daily OLR averaged over $7.5^{\circ} \mathrm{N}-7.5^{\circ} \mathrm{S}$ shown longitude versus day number (left panel) and the same shown for the longitude $138.75^{\circ} \mathrm{E}$ (shown as red-coloured curve) along with the diurnal amplitude at $90 \mathrm{~km}$ over Tirunelveli and the diurnal amplitude of rainfall rate derived for $140^{\circ} \mathrm{E}$ longitude (right panel). The thick curve on the right panel was obtained by smoothing the diurnal rainfall rate (shown as thin curve).

movement can be seen and by day number 65 , the convective clouds have moved to their earlier position of $150^{\circ} \mathrm{E}$ longitude. In the diurnal tide activity in meridional wind, we observed two maxima in amplitudes, one occurring around day number 40 and the other around day number 65 . We performed a correlation analysis for the diurnal tide amplitude and daily OLR and found the largest negative correlation occurring at a longitude around $140^{\circ} \mathrm{E}$ (results not shown here).

In Fig. 7, we show the amplitude of the diurnal tide in meridional wind at $90 \mathrm{~km}$ estimated from the MF radar data set along with the diurnal amplitude of the rainfall rates computed for $140^{\circ} \mathrm{E}$ longitude and the daily OLR averaged over $7.5^{\circ} \mathrm{N}-7.5^{\circ} \mathrm{S}$ shown both for the longitude region $100-155^{\circ} \mathrm{E}$ and the single longitude $138.75^{\circ} \mathrm{E}$. As can be seen in this figure, the temporal variation of the diurnal tide amplitude at $90 \mathrm{~km}$ closely resembles the OLR variation at $138.75^{\circ} \mathrm{E}$ longitude in the low latitude region. Analysis of the diurnal amplitude in the rainfall rate estimated using the TRMM data sets confirms the presence of significant diurnal precipitation rates associated with diurnal variations in latent heat release centred around two periods, namely, day number 45 and day number 65 . A good correlation between the short-period (in a time scale of less than a month) diurnal tide activity at MLT height and the diurnal rainfall rate suggests that the nonmigrating tides were probably generated around those two periods when the diurnal harmonic of latent heat release in the western Pacific region was strongest.

\section{Discussion}

Coordinated efforts from a team of scientists in India had resulted in the successful conduct of the first tidal campaign under the CAWSES-India umbrella. Three ground-based radar experiments and the fortnightly rocket soundings conducted during the period February-April 2006 contributed to this study. Because the MLT radars were each of different kind, the first exercise carried out was to compare the hourly mean winds observed by them. Only the zonal component during daytime agreed reasonably well whereas the meridional wind detected by the SKiYMET system appears to be stronger than what the MF radar detects during daytime. There were some differences in both the wind components during nighttime. In spite of such differences in the mean wind components, the temporal variations in the tidal amplitudes observed over the two sites are quite similar and the phases agree quite well in absolute magnitude.

Earlier comparisons with meteor radar systems showed that the MF radar systems detected smaller wind speeds (e.g. 
Cervera and Reid, 1995; Valentic et al., 1997). Applying the spaced antenna full correlation analysis to the data obtained by the Imaging Doppler interferometer, Turek et al. (1998) found an overall agreement with the winds derived from the incoherent scatter radar at Arecibo during the AIDA '89 campaign. A noticeable discrepancy, however, was found in the meridional winds, with speeds differing up to $50 \mathrm{~m} / \mathrm{s}$. The comparison by Khattatov et al. (1996) with the winds measured by a satellite-borne instrument revealed smaller wind speeds measured by MF radars. The scientific community is aware of such differences and the tidal amplitudes estimated with the MF radar data sets need to be treated with caution.

Two pronounced maxima in diurnal tide amplitudes were observed at the low latitude radar sites during the FebruaryMarch period, especially in the meridional wind, with a time separation of about 20 days and we explored the possibility of linking this variability with variations in deep tropical convection over the western Pacific. Though the cause for this variability in the deep tropical convection close to the maritime continent is yet to be identified, in the light of the model simulations performed by Hagan and Forbes (2002), we reiterate the deep tropical convection occurring over this region as a possible source for generating nonmigrating tides that could attain significant amplitudes in the MLT region and induce variability in the observed tidal amplitudes. A separate analysis carried out by the first author with simultaneous observations of tidal winds carried out at Pontianak and Christmas Island revealed a 30-40 day modulation of tidal amplitudes over all the three sites during the summer monsoon period of 1996 and a similar variation could be noticed in the deep tropical convection occurring in the Indian ocean (results communicated for a possible publication in Earth Planets and Space). The numerical model of Ekanayake et al. (1997) emphasizes the role of background wind in enhancing the amplitudes of nonmigrating tides in the MLT region. This possibility needs to be looked into with further numerical studies and global observations.

Two other height regions were examined in the present work utilizing different kinds of data sets. The periodic rocket soundings over the 3-month duration performed as part of the MIDAS programme had yielded information about the average diurnal characteristics over the low latitude Indian sector. During this period, the MST radar at Gadanki sampled the altitude region $3-25 \mathrm{~km}$ in $4-5$ day diurnal cycles. The largest radar derived tidal amplitudes estimated during this period were in the range $2-3 \mathrm{~m} / \mathrm{s}$ and are in agreement with the earlier report by Sasi et al. (2001). An interesting outcome from combining the results from the rocket and MST radar derived data sets is noted in this work. Though the phase profiles for the lower altitude region reveal random variations in the meridional direction, the phase in the zonal direction on the average is seen to merge with the phase derived from the rocket data.
Acknowledgements. The Middle Atmospheric Dynamics (MIDAS) programmeme under which the fortnightly rocket soundings were carried out was sponsored by the Indian Space Research Organization (ISRO). The authors acknowledge the efforts made by the operational and technical staff at the three radar sites, namely, Trivandrum, Tirunelveli and Gadanki, in running the experiments successfully during the tidal campaign period. This work forms part of the scientific activities pursued by the Indian scientists under the CAWSES-India umbrella which is a national programme sponsored by the Department of Space, Government of India.

Topical Editor U.-P. Hoppe thanks two anonymous referees for their help in evaluating this paper.

\section{References}

Briggs, B. H.: The analysis of spaced sensor records by correlation techniques, MAP Handbook, 3, 166-186, 1984.

Burrage, M. D., Hagan, M. E., Skinner, W. R., Wu, D. L., and Hays, P. B.: Long-term variability in the solar diurnal tide observed by HRDI and simulated by the GSWM, Geophys. Res. Lett., 22, 2641-2644, 1995.

Cervera, M. A. and Reid, I. M.: Comparisons of simultaneous wind measurements using colocated VHF meteor radar and spaced antenna radar systems, Radio Sci., 30, 1245-1261, 1995.

Chang, J. L. and Avery, S.: Observations of the diurnal tide in the mesosphere and lower thermosphere over Christmas Island, J. Geophys. Res., 102, 1895-1907, 1997.

Ekanayake, E. M. P., Aso, T., and Miyahara, S.: Background wind effect on propagation of nonmigrating diurnal tides in the middle atmosphere, J. Atmos. Sol. Terr. Phys., 59, 401-429, 1997.

Forbes, J. M.: Atmospheric tides, I, Model description and results for the solar diurnal component, J. Geophys. Res., 87, 52225240, 1982.

Forbes, J. M., Zhang, X., Talaat, E. R., and Ward, W.: Nonmigrating diurnal tides in the thermosphere, J. Geophys. Res., 108(A1), 1033, doi:10.1029/2002JA009262, 2003.

Gurubaran, S. and Rajaram, R.: Long-term variability in the mesospheric tidal winds observed by MF radar over Tirunelveli (8.7 N, 77.8 E), Geophys. Res. Lett., 26, 1113-1116, 1999.

Gurubaran, S., Rajaram, R., Nakamura, T., and Tsuda, T.: Interannual variability of diurnal tide in the tropical mesopause region: A signature of the El Nino-Southern Oscillation (ENSO), Geophys. Res. Lett., 32, L13805, doi:10.1029/2005GL022928, 2005.

Hagan, M. E.: Comparative effects of migrating solar sources on tidal signatures in the middle and upper atmosphere, J. Geophys. Res., 101, 21 213-21 222, 1996.

Hagan, M. E. and Forbes, J. M.: Migrating and nonmigrating diurnal tides in the middle and upper atmosphere excited by tropospheric latent heat release, J. Geophys. Res., 107(D24), 4754, doi:10.1029/2001JD001236, 2002.

Hagan, M. E. and Roble, R. G.: Modeling diurnal tide variability with the National Center for Atmospheric Research thermosphere-ionosphere-mesosphere-electrodynamics general circulation model, J. Geophys. Res., 106, 24 869-24 882, 2001.

Hagan, M. E., Forbes, J. M., and Vial, F.: On modeling migrating solar tides, Geophys. Res. Lett., 22, 893-896, 1995.

Hamilton, K.: Latent heat release as a possible forcing mechanism for atmospheric tides, Mon. Weather Rev., 109, 3-17, 1981. 
Hocking, W. H., Fuller, B., and Vandepeer, B.: Real-time determination of meteor-related parameters utilizing modern digital technology, J. Atmos. Solar-Terr. Phys., 63, 155-169, 2001.

Khattatov, B. V., Geller, M. A., Yudin, V. A., et al.: Dynamics of the mesosphere and lower thermosphere as seen by MF radars and the High-Resolution Doppler Imager/UARS, J. Geophys. Res., 101, 10393-10 404, 1996.

Lieberman, R. S., Ortland, D. S., and Yarosh, E. S.: Climatology and interannual variability of diurnal water vapor heating, J. Geophys. Res., 108, 4123, doi:10.1029/2002JD002308, 2003.

Lieberman, R. S., Oberheide, J., Hagan, M. E., Remsberg, E. E., and Gordley, L. L.: Variability of diurnal tides and planetary waves during November 1978-May 1979, J. Atmos. Solar-Terr. Phys., 66, 517-528, 2004.

Lindzen, R. S.: Turbulence and stress owing to gravity wave and tidal breakdown, J. Geophys. Res., 86, 9707-9714, 1981.

Lindzen, R. S. and Blake, D.: Internal gravity waves in atmospheres with realistic dissipation and temperature, II, Thermal tides excited below the mesopause, Geophys. Fluid Dyn., 2, 3161, 1971.

McLandress, C.: Seasonal variability of the propagating diurnal tide: Results from the Canadian Middle Atmosphere Model, J. Geophys. Res., 102, 29747-29 764, 1997.

Miyahara, S., Miyoshi, Y., and Yamashita, K.: Variations of migrating and nomigrating tides simulated by the middle atmosphere circulation model at Kyushu University, Adv. Space Res., 24, 1549-1558, 1999.

Oberheide, J. and Gusev, O. A.: Observations of migrating and nonmigating diurnal tides in the equatorial lower thermosphere, Geophys. Res. Lett., 29(24), 2167, 10.1029/2002GL016213, 2002.

Oberheide, J., Wu, Q. L., Killeen, T. L., Hagan, M. E., and Roble, R. G.: Diurnal nonmigrating tides from TIMED Doppler Intererometer wind data: Monthly climatologies and seasonal variations, J. Geophys. Res., 111, A10S03, doi:10.1029/2005JA011491, 2006.

Rajaram, R. and Gurubaran, S.: Seasonal variabilities of the lowlatitude mesosphere, Ann. Geophys., 16, 197-204, 1998, http://www.ann-geophys.net/16/197/1998/.
Ramkumar, G., Antonita, T. M., Bhavani Kumar, Y., Venkata Kumar, H., and Narayana Rao, D.: Seasonal variation of gravity waves in the equatorial middle atmosphere: Results from ISRO's Middle Atmospheric Dynamics (MIDAS) programme, Ann. Geophys., 24, 2471-2480, 2006, http://www.ann-geophys.net/24/2471/2006/.

Rao, P. B., Jain, A. R., Kishore, P., Balamuralidhar, P., Damle, S. H., and Viswanathan, G.: Indian MST radar: 1, System description and sample vector wind measurements in ST mode, Radio Sci., 30, 1125-1138, 1995.

Sasi, M. N.: Geetha Ramkumar, and V. Deepa, Nonmigrating diurnal tides in the troposphere and lower stratosphere over Gadanki (13.5 N, 79.2 E), J. Geophys. Res., 103, 19 485-19494, 1998.

Sasi, M. N., Ramkumar, G., and Deepa, V.: Tidal wind oscillations in the tropical lower atmosphere observed by Indian MST radar, Ann. Geophys., 19, 991-999, 2001, http://www.ann-geophys.net/19/991/2001/.

Talaat, E. R. and Lieberman, R. S.: Nonmigrating diurnal tides in mesospheric and lower thermospheric winds and temperatures, J. Atmos. Sci., 56, 4073-4087, 1999.

Tsuda, T. and Kato, S.: Diurnal non-migrating tides excited by a differential heating due to land-sea distribution, J. Meteorol. Soc. Jpn., 67, 43-54, 1989.

Turek, R. S., Roper, R. G., and Brosnahan, J. W.: Further direct comparisons of incoherent scatter and medium frequency radar winds from AIDA '89, J. Atmos. Terr. Phys., 60, 337-347, 1998.

Valentic, T. A., Avery, J. P., Avery, S. K., and Vincent, R. A.: A comparison of winds measured by meteor radar systems and an MF radar at Buckland Park, Radio Sci., 32, 867-874, 1997.

Vincent, R. A.: MF/HF radar measurements of the dynamics of the mesopause region - A review, J. Atmos. Terr. Phys., 46, 961974, 1984

Vincent, R. A. and Lesicar, D.: Dynamics of the equatorial atmosphere: First results with a new generation partial reflection radar, Geophys. Res. Lett., 18, 825-828, 1991.

Vincent, R. A., Kovalam, S., Fritts, D. C., and Isler, J. R.: Long-term MF radar observations of solar tides in the low latitude mesosphere: Interannual variability and comparisons with GSWM, J. Geophys. Res., 103, 8667-8683, 1998. 